\title{
Update on pulmonary arterial hypertension in children: management strategies and clinical utility of sildenafil
}

This article was published in the following Dove Press journal:

Pediatric Health, Medicine and Therapeutics

8 August 2012

Number of times this article has been viewed

\section{Andrew Wardle \\ Robert Tulloh \\ Bristol Royal Hospital for Children, Bristol, UK}

\begin{abstract}
Pulmonary hypertension is an area of growing interest in cardiology, respiratory, and rheumatic diseases due to the increased treatment that is now available to ameliorate the disease process and the improved survival with such medication. The most common cause of pulmonary hypertension is secondary to congenital heart disease and the availability of a medication that is widely used and familiar in clinical practice enables pediatricians to manage this condition. However, there is much to be learned regarding the indications for this medication, for example, in chronic lung disease, and perioperatively in congenital heart disease. It is not yet clear when the therapy should commence, when the disease is mild or when it has progressed. This article summarizes the current state of knowledge of disease therapy concentrating on the use of sildenafil in the pediatric population.
\end{abstract}

Keywords: pulmonary hypertension, pediatric, sildenafil

\section{Introduction}

Pulmonary arterial hypertension (PAH) is a chronic pan-pulmonary disease implicated in both the morbidity and mortality of a diverse range of conditions and an important cause of progressive right heart failure. Our understanding of PAH has evolved substantially over the past decades and this has facilitated significant improvements in prognosis through enhanced diagnostic techniques and novel second-generation treatment strategies such as sildenafil. However, PAH remains a significant cause of deterioration in quality of life (QOL) and current median child survival for idiopathic pulmonary arterial hypertension (IPAH) stands at just over 4 years. ${ }^{1}$

\section{Definition}

PAH is defined as a resting mean pulmonary artery pressure (pPA) of more than $25 \mathrm{mmHg}$, often seen with a regurgitant velocity across the tricuspid valve of more than $2.8 \mathrm{~m} / \mathrm{s}$ on Doppler echocardiography. However, this must be put into the context of the patient, especially in pediatrics where systemic mean arterial pressure (MAP) may be $50 \mathrm{mmHg}$. Therefore, pulmonary hypertension $(\mathrm{PH})$ is also recognized when the systolic pulmonary to systemic pressure ratio exceeds $0.5 .{ }^{1}$ Pulmonary vascular resistance (PVR) and flow are also important as together they generate pPA (Ohm's and Darcy's laws), and so the diagnosis also requires an elevated PVR $\left(>3\right.$ Wood units $\left.\times \mathrm{BSA} \mathrm{m}^{2}\right)$ with normal capillary wedge pressures ( $\leq 15 \mathrm{mmHg}$ ), which is important in unrepaired congenital heart disease (CHD) where a hyperkinetic pulmonary circulation causes hypertensive pPA pressures due to flow, but without a high PVR in the early months of life..$^{2-4}$
Correspondence: Robert Tulloh Department of Congenital Heart Disease, Bristol Royal Hospital for Children, Upper Maudlin Street,

Bristol BS2 8BJ, UK

Tel +44 II 73428856

Fax +44 II 3428857

Email robert.tulloh@uhbristol.nhs.uk 


\section{Classification}

PAH can be either primary, and therefore idiopathic PAH (IPAH), or secondary, involving independent pathology causing associated PAH (APAH). Furthermore, PAH itself forms just one segment of the $\mathrm{PH}$ spectrum as defined by the World Health Organization (WHO) and the Dana Point 4th World Symposium on Pulmonary Hypertension (illustrated in Table 1). ${ }^{5,6}$

The PAH subdivisions represent the complex etiology of the condition. Moreover, recent changes in classification have distinguished a hereditary form (HPAH) from IPAH, where HPAH describes known inheritance or spontaneous mutations within known PAH-associated genes, and IPAH is purely sporadic and without identifiable cause. Another PAH variant is persistent pulmonary hypertension of the newborn (PPHN). Although classified as PAH, this varies significantly in epidemiology, pathology, and prognosis to other PAH forms and therefore is not extensively covered here.

\section{Functional classification}

The WHO PAH functional class system aids assessment in adults and children. It utilizes symptom occurrence relative to activity level; however, its application to pediatrics is controversial, especially for assessing patients who suffer severe symptoms on exertion (eg, syncope). ${ }^{7}$

\section{Epidemiology}

Unlike adult PAH, where substantial registries record accurate epidemiological data, pediatric registries are less established and do not share the same power, leading to inaccurate estimation of prevalence. ${ }^{8}$ Available data shows a 2:1 female predominance and recent Dutch crosssectional studies found 15.6 cases/million of APAH-CHD and 3.7 cases/million of PAH, excluding PPHN and APAHCHD. ${ }^{9,10}$ However, IPAH may account for 2.2 cases/million of this latter figure. ${ }^{11}$ The high proportion of CHD-APAH highlights the importance of CHD screening when diagnosing PAH.

\section{Survival}

Prognosis is variable depending on the cause and treatment regime. Generally, pediatric IPAH carries a worse prognosis than adult, with an untreated median survival of 1 year after diagnosis compared with 2.8 years in adults. ${ }^{12}$ However, new treatments are considerably improving this outlook. ${ }^{1,13}$ The influence that sildenafil will have on these figures is still being investigated but recent data from a small study indicates significant improvement. ${ }^{14}$ Survival in Eisenmenger syndrome is now up to the fourth or fifth decade and is mainly responsible for the increased prevalence of APAH in the general population.

Table I Dana Point Classification of pulmonary hypertension

\begin{tabular}{|c|c|c|c|}
\hline Group & Condition & Classification & Cause \\
\hline \multirow[t]{17}{*}{ I } & PAH (pulmonary arterial hypertension) & Idiopathic (IPAH) & Sporadic \\
\hline & & & Familial (now known as HPAH) \\
\hline & & Associated (APAH) & Connective tissue disease \\
\hline & & & HIV infection \\
\hline & & & Portal hypertension \\
\hline & & & Congenital heart disease (APAH-CHD) \\
\hline & & & Schistosomiasis \\
\hline & & & Chronic hemolytic anemia \\
\hline & & Heritable (HPAH) & Bone morphogenic receptor type 2 (BMPR2) \\
\hline & & & Activin receptor-like kinase type I (ALKI) \\
\hline & & & Endoglin (with or without telangectasia) \\
\hline & & & Other \\
\hline & & Drug/toxin-induced & \\
\hline & & Persistent pulmonary hypertension & \\
\hline & & of the newborn (PPHN) & \\
\hline & Pulmonary veno-occlusion and/or & & \\
\hline & capillary hemangiomatosis & & \\
\hline 2 & Pulmonary hypertension (PH) secondary & & \\
\hline & to left heart disease & & \\
\hline 3 & Pulmonary hypertension secondary to & & \\
\hline & respiratory disease and/or hypoxemia & & \\
\hline 4 & Chronic thromboembolic PH & & \\
\hline 5 & $\mathrm{PH}$ with unclear or multifactorial reason & & \\
\hline
\end{tabular}

Abbreviations: $\mathrm{PAH}$, pulmonary arterial hypertension. 


\section{Pathophysiology}

PAH is principally a disorder of pulmonary vascular tone secondary to increases in vascular smooth muscle cell (VSMC) number and contractile state. This itself is the product of extracellular-matrix degradation and changes in local mediators including reduced prostaglandins alongside increased thromboxane and plasma endothelin levels. ${ }^{15,16}$ Furthermore, the VSMC contractile state is also regulated by endothelial cells; however, changes in these cells represented by fibrinoid necrosis and plexogenic lesions can cause a treatment-refractory lumen occlusion. ${ }^{17}$ The chronic overactivation of the aforementioned systems causes histological pulmonary vasculature changes; most notably, there is increased central vascular musculature alongside peripheral neomuscularization, leading to an increased strain on the right heart that can instigate failure and death. ${ }^{18}$

The most prominent genetic mutations involve the cell receptors of the Smad system (BMPR-2 and Alk-1) whereby resultant cascades alter transforming growth factor- $\beta$ signaling and prompt defective pulmonary cell migration and apoptosis. ${ }^{19}$ When reviewing PAH genetics, a physician must also recognize and understand that the majority of the population with such mutations does not actually suffer PAH and therefore any PAH genetic information requires careful management.

Guided therapy decision making might be underpinned by VSMC contraction mechanism knowledge. This includes the idea of a dependence on cytoplasmic calcium concentrations that can be reduced via cyclic guanine monophosphate (cGMP)-mediated sarcoplasmic reticulum uptake. Therefore, increasing cGMP concentrations can inhibit contraction and the triggering of vasodilatation. This is achieved by preventing cGMP degradation (eg, phosphodiesterase-V $[\mathrm{PDE}-\mathrm{V}]$ inhibitors), or by stimulating cGMP creation (eg, nitric oxide [NO]).

Current understanding of PAH is reliant on studies based on animals and adult humans, and therefore pediatric pathology, where alveolar growth and vasculature development link and the state of either is complicated by incomplete lung maturation, may differ. ${ }^{20}$ This is exemplified by the increased capacity for PAH pathology in children relative to adults and is key when identifying new pediatric treatments. ${ }^{21}$

\section{Clinical presentation}

Antecedent histories are an invaluable source of information, especially in the context of previous $\mathrm{PAH}$, pulmonary hypoplasia, or sudden unexplained death among the immediate family. Clinicians should also suspect previously diagnosed severe asthma not presenting with wheeze upon exertion, as this may be an earlier PAH misdiagnosis.

The most common IPAH presentation is dyspnea with fatigue upon exertion, although exercise-induced syncope, chest pain, and a loud P2 are all probable. ${ }^{22}$ More rarely, patients can present with right heart failure, hemoptysis, or cyanosis - the latter two being especially important in neonates. ${ }^{23}$ Of course, in many patients, the presentation is that of known congenital heart disease (CHD) and ongoing follow-up for pulmonary vascular disease.

The diagnostic procedures for pediatric $\mathrm{PAH}$ are consistent with those recommended by the European Society of Cardiology/European Respiratory Society for adults. ${ }^{24}$ Common investigations include chest radiography, surface electrocardiography, and trans-thoracic echocardiography among others, including the rise in relevance of magnetic resonance imaging.

\section{Down syndrome}

Trisomy 21 is one of the most commonly diagnosed genetic defects in the Western world and is associated with CHD and upper airway obstruction, both of which lead to PAH. Yet despite a relatively large PAH incidence in this population, little has been published regarding diagnosis and treatment in this group, but this is now beginning to change. ${ }^{12,25}$

\section{Pediatric treatment considerations}

PAH necessitates long-term multiprofessional specialist care alongside extensive community-based family support. ${ }^{24}$ Treatment response is more difficult to predict than among adults and therefore close monitoring with appropriate alteration is imperative to prevent the need for lung transplantation. ${ }^{26}$ However, due to a limitation in high-quality pediatric evidence, current PAH guidelines are the product of consensus and the extrapolation of adult trial data. ${ }^{27}$ The validity of using such data is compromised by both disease prognosis and subtype prevalence, with greater incidence of APAH-CHD and less IPAH in pediatrics. ${ }^{28}$ Caution must also be observed when reviewing the pediatric trials that are available as study populations are often non-Gaussian in age range with a bias toward older children who may not reflect the same response or disease process as infants and toddlers.

\section{Treatment}

Long-term treatment aims to reduce pulmonary vascular disease progression while improving function, QOL, and survival. Current WHO guidelines state that therapy 
should be dictated according to WHO functional class and catheter-derived vasodilator responses. ${ }^{26}$ However, other less objective patient characteristics should also be considered, especially in pediatrics, as the regimen can require high levels of compliance and cause significant adverse effects. Furthermore, the initiation of such strategies is complicated by variable worldwide treatment availability due to high cost and potential adverse consequences. For these reasons, strategies should be started and monitored by physicians with extensive PAH experience wherever possible. Calcium channel blockers, prostanoid analogs, and endothelin antagonists form the mainstay of treatment; however, this is now gradually beginning to change due in part to the advent of sildenafil.

\section{Acute treatment}

This can take the form of inhalation (nitric oxide [NO]), oral or intravenous therapies (sildenafil), intravenous therapies (epoprostenol), and/or hemodynamic support (extracorporeal membrane oxygenation). ${ }^{29,30}$ Coupled with this, it is vital to initiate essential care such as oxygen therapy, chest physiotherapy, ventilation, and antibiotics if required. Management aims to maintain optimal airway dynamics to reduce $\mathrm{pPA}$ - this requires low airway pressure with good oxygenation and low carbon dioxide content, as well as a slightly alkaloid $\mathrm{pH}$.

\section{NO}

Physiologically, NO stimulates guanylyl cyclase, increasing VSMC cGMP, and hence causing vasodilatation with associated pPA and PVR reductions facilitating better oxygenation. When given exogenously, its effects are largely confined to the pulmonary vasculature due to rapid peripheral inactivation by hemoglobin. ${ }^{30}$ Nevertheless, sustained high doses can cause met-hemoglobinemia. ${ }^{31}$ Such doses may be avoidable using sildenafil, which is synergistic to NO therapy due to the augmentation of endogenous NO sources that can complement the exogenous NO source provided by inhalation. ${ }^{32}$

Sildenafil is also useful in NO therapy withdrawal-related rebound pulmonary hypertension. ${ }^{33}$ This is an avoidable situation using the promotion of endogenous NO synthesis via prostacyclin, half-dose NO therapy, or, as already stated, sildenafil. ${ }^{34}$

Conversely, porcine models have proven this combination to cause systemic hypotension and reduced oxygenation, and similar effects have been noted post-CHD repair in neonates. ${ }^{35,36}$ This may be due to excessive vasodilatation within a relatively hypoxic pulmonary vasculature causing a reduction in oxygenation efficiency. Interestingly, in PPHN there is elevated expression and activity of PDE-V, and therefore the tolerance of this combination may be superior to other PAH forms. ${ }^{37}$

\section{Chronic sildenafil}

Sildenafil is a widely used PDE-V inhibitor (PDE-Vi) and the first US Food and Drug Administration-approved oral NO-augmentation strategy for moderate and severe PAH. ${ }^{38}$ It is licensed for both pediatric and adult patient groups under the name 'Revatio.' However, the use of 'Viagra' in 'blue babies' can still be controversial with parents. ${ }^{39,40}$ The trial data supporting sildenafil in pediatric PAH is promising. Additionally, its low cost and toxicity alongside easy compliance relative to the alternatives has ensured its firm integration into the PAH armory.

\section{Pharmacodynamics}

By inhibiting PDE-V, levels of which increase in PAH, sildenafil reduces cGMP catabolism leading to VSMCmediated vasodilatation. ${ }^{41,42}$ It also possesses anti-VSMC proliferation properties, an advantageous property given PAH pathology. ${ }^{43} \mathrm{PDE}-\mathrm{V}$ inhibition also prevents endothelindependent increases in matrix metalloproteinase-2. ${ }^{44}$ This reduces matrix protein degradation, a critical element in PAH. This same mechanism also inhibits the downstream Rho-associated kinase signaling that normally instigates VSMC contraction and proliferation, thereby reducing $\mathrm{PAH}$ progression. ${ }^{45,46}$

It is not clear whether there is an endothelial-dependent vasodilatation involving reduced endothelin and von Willebrand factor, and increases in endothelial progenitor cells that may facilitate longer-term improvements in endothelial cell function. ${ }^{47,48}$ Evidence also supports elevated PDE-V within the hypertrophied right ventricles of PAH, which has facilitated hypotheses regarding the potential of sildenafil to also improve right ventricular contractility. ${ }^{49}$

\section{Pharmacokinetics}

Sildenafil is rapidly absorbed via the gut with maximal dose-dependent serum concentrations reached within 0.5-1.5 hours of oral administration and a bioavailability of $40 \%{ }^{50}$ Improvements in exercise tolerance are relatively dosedependent; however, in pediatrics, quantities can be variable. ${ }^{51}$ Generally speaking, administration every 6-8 hours with daily dose equivalents between $1-5 \mathrm{mg} / \mathrm{kg}$ are used, although some neonates can tolerate doses of $8 \mathrm{mg} / \mathrm{kg} /$ day. ${ }^{52,53}$ 
Sildenafil has a half-life of approximately 4 hours before metabolism by CYP3A4 and CYTP2C9 of the cytochrome P450 system. However, in pediatrics, this system has two potential major flaws. Firstly, cytochrome P450 interacts with many commonly used drugs that either inhibit (eg, clarithromycin) or induce (eg, phenytoin) its function, which can prompt unpredictable sildenafil plasma levels either above or below the therapeutic window respectively. Secondly, cytochrome P450 can require time to mature after birth; this is especially relevant to neonates, where half-lives can be longer than anticipated leading to an associated greater potential for adverse effects. ${ }^{54}$ There is now availability of intravenous sildenafil, primarily used to cover those patients who are usually maintained on an oral dose. The increased bioavailability means that a small dose, usually $0.5 \mathrm{mg} / \mathrm{kg}$, can be given each 8 hours.

In addition to these points, there has also been suggestion of long-term sildenafil treatment resistance; however, data regarding this is lacking and the use of concurrently inhaled-NO may avoid this. ${ }^{55}$

\section{Adverse effects}

Commonly recognized side effects include abdominal discomfort, dizziness, flushing, headaches, and nausea, as well as the potential for notable long-term memory loss. ${ }^{56,57}$ Some of these effects can be easily managed, for example using acetaminophen to avoid headaches; however, others may prove more problematic. Despite their number, these adverse reactions are still substantially less significant than other current PAH alternatives, especially with reference to detrimental renal or hepatic functions. ${ }^{58}$ Traditionally, there has also been an association between PDE-Vi's and impaired retinal function, yet a recent 6-month assessment comparing both sildenafil and tadalafil with placebo found no significant risk, helping to dispel such thoughts. ${ }^{59}$

\section{Sildenafil monotherapy}

In 2005, a 14-person 12-month trial of sildenafil $(0.25-1 \mathrm{mg} / \mathrm{kg}$ four times daily) in childhood IPAH and APAH-CHD was published.$^{47}$ It reported significantly improved hemodynamics (median pPA improved from $60 \mathrm{mmHg}$ to $50 \mathrm{mmHg}$, $P=0.014$ ) and 6-minute walking distances (6MWD) (from 278 to $432 \mathrm{~m}, P=0.005$ ), and these effects have now also been replicated in APAH-CHD, where the WHO functional class also improved. ${ }^{44}$ These data have now been reinforced by a randomized controlled trial (RCT) demonstrating good childhood efficacy and safety as well as data identifying the optimal dosing of $20 \mathrm{mg}$ three times daily for weights
20-45 kg, with lower doses conferring insufficient hemodynamic benefit and higher doses decreasing long-term survival. ${ }^{60,61}$ Put together, this evidence gives both a strong and positive indication of potential pediatric utility. Furthermore, there may also be further monotherapy applications in PPHN, CHD, and neonatal chronic lung disease. ${ }^{62,63}$

\section{Sildenafil combination}

Combination strategies are recommended in adult PAH when a WHO functional class of III is retained despite treatment. ${ }^{64}$ However, many physicians remain unsure about how best to initiate such therapies, with confusion surrounding staged vs concurrent initiation schedules despite detailed work on this issue.$^{65}$ Alongside this, little data exists regarding proven pediatric applications.

\section{Prostacyclin analogs}

Prostacyclin analogs act upon cyclic adenosine monophosphate (cAMP) signaling in VSMCs to bring about vasodilatation. In doing this, they reduce PVR and VSMC proliferation and platelet aggregation while improving hemodynamic function and QOL ${ }^{6}{ }^{6}$ This mechanism is completely independent of NO-directed therapies, meaning their effect alongside cGMP-mediated approaches is both unfettered by previous cGMP treatment and additive ${ }^{67}$ This is extremely useful clinically, particularly in NO-therapy-resistant patients or those requiring NO weaning. ${ }^{58}$ However, due to their physiological importance, prostacyclin analogs are associated with significant adverse effects including headaches, jaw pain, rashes, thrombocytopenia, and flushing, all of which should be screened for when taking histories. There is currently a wide variety of approved analog formulations aiding their suitability to pediatrics, although the goldstandard treatment epoprostenol requires continuous intravenous administration via central line, a complicated and hazardous approach. Alternative options include intravenous (treprostinil), oral (teraprost), and inhalant (iloprost) routes, although efficacy for PAH can vary notably between these formulations.

More recently, trials have investigated sildenafil alongside prostaglandins. Sixteen-week adult trials using sildenafil in the context of established epoprostenol treatment improved hemodynamic parameters (pPA change: $-2.8 \mathrm{mmHg}$ [sildenafil] vs $+1.1 \mathrm{mmHg}$ [placebo], $P<0.05$ ), and 6MWDs (29.8 m [sildenafil] vs $1.0 \mathrm{~m}$ [placebo], $P<0.05$ ), although this combination was also associated with greater headaches and dyspepsia. ${ }^{68}$ Similar improvements in adults have been yielded with iloprost, where the benefits were extended for 
up to 12 months without sign of the commonly experienced iloprost monotherapy treatment resistance. ${ }^{69}$ This is a very important finding when considering the now-increased survival times of these patients. The adult TRIUMPH study has also revealed 6MWD and QOL benefits using the combination of sildenafil with treprostinil, although as with the above data, pediatric evidence is still required. ${ }^{70}$ The above information highlights the important potential for augmentation of gold-standard prostacyclin analogs with sildenafil in PAH, although before wide-scale clinical use in pediatrics is recommended, substantial research is required in this age group.

\section{Endothelin antagonists}

Endothelin-1 (ET-1) acts upon VSMC and endothelial cells through $\mathrm{ET}_{\mathrm{A}}$ and $\mathrm{ET}_{\mathrm{B}}$ receptors, and the antagonism of this system produces a net NO and prostaglandin-dependent vasodilatation via endothelial $\mathrm{ET}_{\mathrm{B}}$ receptors. Dual antagonists (bosentan) and more-selective antagonists (ambrisentan) have both shown noteworthy efficacy in adult and pediatric PAH populations. ${ }^{71}$ However, hepatic toxicity has held this class back, especially in light of the recent recall of sitaxsentan.

Clinical evidence combining ET-1 antagonists with PDEVi's in those non-responsive to monotherapy is currently only in case study format; however, this has helped pave the way for multiple ongoing trials including COMPASS and ARENA series. ${ }^{72}$

\section{Other combinations}

Strategies employing agents typically not used in $\mathrm{PAH}$ also show potential. Preliminary animal studies combining sildenafil with simvastatin illustrated positive cooperativity whereby the combined effect of both exceeded that of either individually. The mechanism of action for this is hypothesized to rebalance BMPR-2 signaling, suggesting that this strategy may be particularly effective in HPAH, and acts as a prime example of the potential for sildenafil combinations outside of the typical PAH arsenal. ${ }^{73}$

\section{Alternative phosphodiesterase inhibitors}

Sildenafil is not the only PDE-Vi used in erectile dysfunction, and therefore alternative inhibitors may also have potential in PAH. This is especially useful if these choices prove cheaper, more efficacious, or less adversely problematic than sildenafil.

Tadalafil is a long-acting PDE-Vi recently approved by the FDA for chronic adult PAH, as well as showing potential as an adjunct to intravenous prostacyclin in severe PAH.
In adults, monotherapy produces elevated exercise and functional capacities. ${ }^{74,75}$ Nevertheless, current evidence and anecdotal experience of its effect in children is limited, but given its recent step forward in licensing and the rate of advancement of the field, the prospects for its pediatrics application remain promising.

A third PDE-Vi, vardenafil, has also shown positive in-vitro results, and these exceed those of sildenafil. ${ }^{76}$ This may be due to off-target calcium channel blockade, a feature that may enable a novel target combination for PAH. ${ }^{77}$ A recent RCT reinforced these findings, concluding both safety and efficacy for adult PAH, although pediatric application remains elusive. ${ }^{78}$ Briefly stated, vardenafil holds perhaps the greatest potential of all PDE-Vi's currently marketed.

There has also been investigation into PDE inhibitors other than type V. For example, milrinone is a PDE-III inhibitor commonly used in pediatrics for its positive inotropic effects, yet there are increasing data supporting its use in PAH. Its PAH therapeutic mechanisms lie closer to those of prostaglandin analogs, utilizing elevations in cAMP to increase oxygenation in those responding poorly to inhaled NO. This has been demonstrated in two infant PPHN case-series where inhaled NO therapy had already been implemented. ${ }^{79,80}$ Additionally, there is further evidence in those children who had undergone the Fontan operation. ${ }^{81}$

\section{Surgery}

It is important for both patients and medical professionals to realize that there are some patients who will not respond to any of the aforementioned treatments and who are more suited to surgical intervention, for example, in those with chronic thromboembolic pulmonary hypertension who will benefit from thromboendarterectomy, which is fortunately rare in children. There is also some evidence of success when used as either prophylaxis or treatment for post-operative $\mathrm{PH}$, although at the current time, this does not seem to alter the long-term outlook. ${ }^{82,83}$

\section{Research}

There are currently numerous ongoing trials regarding sildenafil in various drug combinations. However, one approach that has not yet reached trial stages involves a change in preparation from sildenafil citrate to sildenafil nitrate, the latter also acting as an exogenous NO donator. This could increase vasodilator potency but may also risk systemic hypotension, which may be avoided by using inhalant formulations. 
Alternatively, zaprinast, an agent recently found to significantly inhibit PDE-I as well as PDE-V, can greatly enhance inhaled NO mediated pulmonary vasodilatation in neonatal lambs. ${ }^{84}$ Elevations of PDE-I have been found within the VSMC of adult PAH pulmonary arteries and this has generated hypotheses regarding its role in human PAH pathology ${ }^{85,86}$ By targeting both arms of PDE, Zaprinast may have greater efficacy than other types of PDE inhibitor.

\section{Conclusion}

This article demonstrates the complexities of pediatric PAH and the opportunities that sildenafil may present. It also highlights the need for extensive monitoring once therapy is initiated due to adverse effects, treatment resistance, and alteration of disease course. Furthermore, much of our current pediatric data is liable to compromise by extrapolation from adult trials, and although this approach has worked well so far, it remains to be seen whether long-term therapy during developmental periods has any effect on the corresponding risk-benefit balance. Put simply, given the substantial increase yet remaining gaps in our current knowledge base, the utility of sildenafil and its related compounds in pediatric PAH remains both an exciting and evolving field.

\section{Disclosure}

The authors report no conflicts of interest in this work.

\section{References}

1. Haworth SG, Hislop AA. Treatment and survival in children with pulmonary arterial hypertension: the UK Pulmonary Hypertension Service for Children 2001-2006. Heart. 2009;95:312-317.

2. Gibbs J. Recommendations on the management of pulmonary hypertension in clinical practice. Heart. 2001;86 Suppl 1:1-13.

3. Badesch DB, Champion HC, Sanchez MA, et al. Diagnosis and assessment of pulmonary arterial hypertension. $\mathrm{J} \mathrm{Am} \mathrm{Coll} \mathrm{Cardiol.}$ 2009;54(Suppl 1):S55-S66.

4. Hill KD, Lim DS, Everett AD, et al. Assessment of pulmonary hypertension in the pediatric catheterisation laboratory. Cardio Vascular Intervention. 2010;76:865-873.

5. Humbert M, Mclaughlin VV. The 4th World Symposium on Pulmonary Hypertension. J Am Coll Cardiol. 2009;54:S1-S2.

6. Simmoneau G, Robbins IM, Beghetti M, et al. Updated clinical classification of pulmonary hypertension. J Am Coll Cardiol. 2009;54: S43-S54.

7. Gorenflo M, Nelle M, Schnabe PA, Ullman MV. Pulmonary hypertension in infancy and childhood. Cardiol Young. 2003;13:219-227.

8. Laura R, Van Loon RL, Roofthooft MTR, Delhaas T, et al. Outcome of pediatric patients with pulmonary artery hypertension. Am J Cardiol. 2010;106:117-124.

9. Badesch DB, Raskob GE, Elliott CG, et al. Pulmonary arterial hypertension: baseline characteristics from the REVEAL registry. Chest. 2010;137:376-387.

10. van Loon RL, Roofthooft MT, Hillege HL, et al. Pediatric pulmonary hypertension in The Netherlands: epidemiology and characterization during the period 1991 to 2005. Circulation. 2011;124(16): $1755-1764$.
11. Fraisse A, Jais X, Schleich JM, et al. Characteristics and prospective 2-year follow-up of children with pulmonary arterial hypertension in France. Arch Cardiovasc Dis. 2010;103:66-74.

12. Barst RJ, Maislin G, Fishman AP. Vasodilator therapy for primary pulmonary hypertension in children. Circulation. 1999;99(9): 1197-1208.

13. Hawkins A, Langton-Hewer S, Henderson J, Tulloh R. Management of pulmonary hypertension in Down syndrome. Eur J Pediatr. 2011; 170:915-921.

14. Zeng WJ, Sun YJ, Gu Q, Xiong CM, Li JJ, He JG. Impact of sildenafil on survival of patients with idiopathic pulmonary arterial hypertension. J Clin Pharmacol. September 28, 2011. [Epub ahead of print.]

15. Tudor A, Muşat A, Bari M, Peța D, Cochior D. Observations on peripheral microcirculation in young hypertensive patients. Rom $J$ Intern Med. 2005;43(1-2):73-78.

16. Cacoub P, Dorent R, Nataf P, Carayon A. Endothelin-1 in pulmonary hypertension. N Engl J Med. 1993;329(26):1967-1968.

17. Jeffery TK, Morrell NW. Molecular and cellular basis of pulmonary vascular remodelling in pulmonary hypertension. Prog Cardiovasc Dis. 2002;45:173-202.

18. Rabinovitch M, Haworth S, Castaneda AR, et al. Lung biopsy in congenital heart disease: a morphometric approach to pulmonary vascular disease. Circulation. 1978;58:1107-1122.

19. Derynck R, Zhang YE. Smad-dependent and Smad-independent pathways in TGF family signalling. Nature. 2003;425:577-584.

20. Thebaud B, Abman SH. Bronchopulmonary dysplasia: where have all the vessels gone? Roles of angiogenic growth factors in chronic lung disease. Am J Respir Crit Care Med. 2007;175:978-985.

21. Barst RJ, Ertel SI, Beghetti M, Ovy DD. Pulmonary arterial hypertension: a comparison between children and adults. Eur Respir J. 2011;37(3):665-677.

22. Van Loon RL, Roofthooft MT, van Osch-Gevers M, et al. Clinical characterization of pediatric pulmonary hypertension: complex presentation and diagnosis. J Pediatr. 2009;155:176-182.

23. Rosenzweig EB, Barst RJ. Idiopathic pulmonary arterial hypertension in children. Curr Opin Pediatr. 2005;17(3):372-380.

24. National Pulmonary Hypertension Centres of the UK and Ireland. Consensus statement on the management of pulmonary hypertension in clinical practice in the UK and Ireland. Thorax. 2008;63:ii1-ii41.

25. Tulloh R. Congenital heart disease in relation to pulmonary hypertension in paediatric practice. Paediatr Respir Rev. 2005;6:174-180.

26. Adriaenssens T, Delcroix M, Van Deyk K, Budts W. Advanced therapy may delay the need for transplantation in patients with the Eisenmenger syndrome. Eur Heart J. 2006;27(12):1472-1477.

27. Galie N, Hoeper MM, Humbert M, et al. Guidelines for the diagnosis and treatment of pulmonary hypertension. Eur Respir J. 2009;34: $1219-1263$.

28. Moledina S, Hislop AA, Foster H, et al. Childhood Idiopathic pulmonary hypertension: a national cohort study. Heart. 2010;96:1401-1406.

29. Taylor CJ, Derrick G, McEwan A, et al. Risk of cardiac catheterization under anaesthesia in children with pulmonary hypertension. $\mathrm{Br} \mathrm{J}$ Anaesth. 2007;98:657-661.

30. Thébaud B, Arnal JF, Mercier JC, Dinh-Xuan AT. Inhaled and exhaled nitric oxide. Cell Mol Life Sci. 1999;55(8-9):1103-1112.

31. Abman SH. Neonatal pulmonary hypertension: a physiologic approach to treatment. Pediatr Pulmonol Suppl. 2004;26:127-128.

32. Atz AM, Lefler AK, Fairbrother DL, Uber WE, Bradley SM. Sildenafil augments the effect of inhaled nitric oxide for postoperative pulmonary hypertensive crises. J Thorac Cardiovasc Surg. 2002;124(3): 628-629.

33. Namachivayam P, Theilen U, Butt WW, Cooper SM, Penny DJ, Shekerdemian LS. Sildenafil prevents rebound pulmonary hypertension after withdrawal of nitric oxide in children. Am J Respir Crit Care Med. 2006;174(9):1042-1047.

34. Hermon M, Golej J, Burda G, Marx M, Trittenwein G, Pollak A. Intravenous prostacyclin mitigates inhaled nitric oxide rebound effect: A case control study. Artif Organs. 1999;23(11):975-978. 
35. Shekerdemian LS, Ravn HB, Penny DJ. Interaction between inhaled nitric oxide and intravenous sildenafil in a porcine model of meconium aspiration syndrome. Pediatr Res. 2004;55(3):413-418.

36. Stocker C, Penny DJ, Brizard CP, Cochrane AD, Soto R, Shekerdemian LS. Intravenous sildenafil and inhaled nitric oxide: a randomised trial in infants after cardiac surgery. Intensive Care Med. 2003;29(11): 1996-2003.

37. Farrow KN, Lakshminrusimha S, Czech L, et al. SOD and inhaled nitric oxide normalize phosphodiesterase 5 expression and activity in neonatal lambs with persistent pulmonary hypertension. Am J Physiol Lung Cell Mol Physiol. 2010a;299(1):L109-L116.

38. Reffelmann T, Kloner RA. Therapeutic potential of phosphodiesterase 5 inhibition for cardiovascular disease. Circulation. 2003;108(2): 239-244.

39. Oliver J, Webb DJ. Sildenafil for 'blue babies.' Such unlicensed drug use might be justified as last resort. BMJ. 2002;325:1174.

40. Patole S, Travadi J. Sildenafil for 'blue babies.' Ethics, conscience, and science have to be balanced against limited resources. BMJ. 2002; 325:1174.

41. Murray F, MacLean MR, Pyne NJ. Increased expression of the cGMP inhibited cAMP-specific (PDE3) and cGMP binding cGMP-specific (PDE5) phosphodiesterases in models of pulmonary hypertension. $\mathrm{Br}$ J Pharmacol. 2002;137:1187-1194.

42. Weimann J, Ullrich R, Hromi J, et al. Sildenafil is a pulmonary vasodilator in awake lambs with acute pulmonary hypertension. Anesthesiology. 2000;92(6):1702-1712.

43. Wharton J, Strange JW, Moller GM, et al. Antiproliferative effects of phosphodiesterase type 5 inhibition in human pulmonary artery cells. Am J Respir Crit Care Med. 2005;172:105-113.

44. Sun X, Li Z, Liu Y, Fang P, Li M. Inhibition of cGMP phosphodiesterase 5 suppresses matrix metalloproteinase-2 production in pulmonary artery smooth muscle cells. Clin Exp Pharmacol Physiol. 2010;37: 362-367.

45. Broughton BR, Walker BR, Resta TC. Chronic hypoxia induces Rho kinase-dependent myogenic tone in small pulmonary arteries. Am J Physiol Lung Cell Mol Physiol. 2008;294:L797-L806.

46. McNamara PJ, Murthy P, Kantores C, et al. Acute vasodilator effects of Rho-kinase inhibitors in neonatal rats with pulmonary hypertension unresponsive to nitric oxide. Am J Physiol Lung Cell Mol Physiol. 2008;294:L205-L213.

47. Rossi R, Nuzzo A, Lattanzi A, Coppi F, Modena MG. Sildenafil improves endothelial function in patients with pulmonary hypertension. Pulm Pharmacol Ther. 2008;21(1):172-177.

48. Diller GP, van Eij1 S, Okonko DO, et al. Circulating endothelial progenitor cells in patients with Eisenmenger syndrome and idiopathic pulmonary arterial hypertension. Circulation. 2008;117(23):3020-3030.

49. Nagendran J, Archer SL, Soliman D, et al. PDE5 is highly expressed in the hypertrophied human right ventricle and acute inhibition of PDE5 improves contractility. Circulation. 2007;116:238-248.

50. Karatza AA, Bush A, Magee AG. Safety with pulmonary hypertension. Int J Cardiol. 2005;100:267-273.

51. Bharani A, Mathew V, Sahu A, et al. The efficacy and tolerability of sildenafil in patients with moderate-to-severe pulmonary hypertension. Indian Heart J. 2003;55:55-59.

52. Carroll WD, Dhillon R. Sildenafil as a treatment for pulmonary hypertension. Arch Dis Child. 2003;88:827-828.

53. Michelakis ED, Tymchak W, Noga M. Long term treatment with oral sildenafil is safe and improves functional capacity and hemodynamics in patients with pulmonary arterial hypertension. Circulation. 2003;108: 2066-2069.

54. Mukherjee A, Dombi T, Wittke B, Lalonde R. Population pharmacokinetics of sildenafil in term neonates: evidence of rapid maturation of metabolic clearance in the early postnatal period. Clin Pharmacol Ther. 2009;85(1):56-63.

55. Spring RM, Ulrich S, Huber LC, et al. Sildenafil for pulmonary hypertension: dose-dependent improvement in exercise performance. Pulm Pharmacol Ther. 2008;21(3):516-521.
56. Lee SH, Rubin LJ. Current treatment strategies for pulmonary arterial hypertension. J Intern Med. 2005;258(3):199-215.

57. Della Torre F, Della Torre E, Di Berardino F. Sildenafil in pulmonary hypertension. Sarcoidosis Vasc Diffuse Lung Dis. 2005;22(1):78-79.

58. Humpl T, Reyes JT, Holtby H, Stephens D, Adatia I. Beneficial effect of oral sildenafil therapy on childhood pulmonary arterial hypertension: twelve-month clinical trial of a single drug, open-label, pilot study. Circulation. 2005;111:3274-3280.

59. Cordell WH, Maturi RK, Costigan TM, et al. Retinal effects of 6 months of daily use of tadalafil or sildenafil. Arch Ophthalmol. 2009;127: 367-373.

60. Barst R, Richardson H, Konourina I. Oral sildenafil treatment in children with pulmonary arterial hypertension (PAH): results of a double-blind, placebo-controlled, dose-ranging study. Eur Respir J. 2009;34:3S-4S

61. Barst RJ, Ivy DD, Gaitan G, et al. A randomized, double-blind, placebocontrolled, dose-ranging study of oral sildenafil citrate in treatmentnaive children with pulmonary arterial hypertension. Circulation. 2012; 125(2):324-334.

62. Steinhorn RH, Kinsella JP, Pierce C, et al. Intravenous sildenafil in the treatment of neonates with persistent pulmonary hypertension. J Pediatr. 2009;155:841. e1-847. e1.

63. Mourani PM, Sontag MK, Ivy DD, Abman SH. Effects of long term sildenafil treatment for pulmonary hypertension in infants with chronic lung disease. J Pediatr. 2009;154:379-384.

64. Barst RJ, Gibbs JS, Ghofrani HA, et al. Updated evidence-based treatment algorithm in pulmonary arterial hypertension. $\mathrm{J}$ Am Coll Cardiol. 2009;54(Suppl 1):S78-S84.

65. Hoeper MM, Markevych I, Spiekerkoetter E, et al. Goal-oriented treatment and combination therapy for pulmonary arterial hypertension. Eur Respir J. 2005;26:858-863.

66. Rosenzweig EB, Kerstein D, Barst RJ. Long-term prostacyclin for pulmonary hypertension with associated congenital heart defects. Circulation. 1999;99(14):1858-1865.

67. Rosenzweig EB, Widlitz AC, Barst RJ. Pulmonary arterial hypertension in children. Pediatr Pulmonol. 2004;38(1):2-22.

68. Simonneau G, Rubin LJ, Galie N, et al. Addition of sildenafil to long term intravenous epoprostenol therapy in patients with pulmonary arterial hypertension: a randomized trial. Ann Intern Med. 2008;149: 521-530.

69. Ghofrani HA, Rose F, Schermuly RT, et al. Oral sildenafil as longterm adjunct therapy to inhaled iloprost in severe pulmonary arterial hypertension. J Am Coll Cardiol. 2003;42:158-164.

70. McLaughlin VV, Benza RL, Rubin LJ, et al. Addition of inhaled treprostinil to oral therapy for pulmonary arterial hypertension: a randomized controlled clinical trial. J Am Coll Cardiol. 2010;55: 1915-1922.

71. Maiya S, Hislop AA, Flynn Y, Haworth SG. Response to bosentan in children with pulmonary hypertension. Heart. 2006;92:664-670.

72. Mogollon MV, Lage E, Cabezon S, et al. Combination therapy with sildenafil and bosentan reverts severe pulmonary hypertension and allows heart transplantation [case report]. Transplant Proc. 2006; 38(8):2522-2523.

73. Kuang T, Wang J, Pang B, et al. Combination of sildenafil and simvastatin ameliorates monocrotaline-induced pulmonary hypertension in rats. Pulm Pharmacol Ther. 2010;23(5):456-464.

74. Galie N, Brundage BH, Ghofrani HA, et al. Tadalafil therapy for pulmonary arterial hypertension. Circulation. 2009;119: 2894-2903.

75. Barst RJ, Oudiz RJ, Beardsworth A, et al; Pulmonary Arterial Hypertension and Response to Tadalafil (PHIRST) Study Group. Tadalafil monotherapy and as add-on to background bosentan in patients with pulmonary arterial hypertension. J Heart Lung Transplant. 2011;30(6): 632-643.

76. Teixeira CE, Priviero FB, Webb RC. Differential effects of the phosphodiesterase type 5 inhibitors sildenafil, vardenafil, and tadalafil in rat aorta. J Pharmacol Exp Ther. 2006;316(2):654-661. 
77. Toque HA, Teixeira CE, Priviero FB, Morganti RP, Antunes E, De Nucci G. Vardenafil, but not sildenafil or tadalafil, has calciumchannel blocking activity in rabbit isolated pulmonary artery and human washed platelets. Br J Pharmacol. 2008;154(4):787-796.

78. Jing ZC, Yu ZX, Shen JY, et al; Efficacy and Safety of Vardenafil in the Treatment of Pulmonary Arterial Hypertension (EVALUATION) Study Group. Vardenafil in pulmonary arterial hypertension: a randomized, double-blind, placebo-controlled study. Am J Respir Crit Care Med. 2011;183(12):1723-1729.

79. Bassler D, Choong K, McNamara P, Kirpalani H. Neonatal persistent pulmonary hypertension treated with milrinone: four case reports. Biol Neonate. 2006;89(1):1-5.

80. McNamara PJ, Laique F, Muang-In S, Whyte HE. Milrinone improves oxygenation in neonates with severe persistent pulmonary hypertension of the newborn. J Crit Care. 2006;21(2):217-222.

81. Cai J, Su Z, Shi Z, et al. Nitric oxide and milrinone: combined effect on pulmonary circulation after Fontan-type procedure: a prospective, randomized study. Ann Thorac Surg. 2008;86(3):882-888.
82. Fraisse A, Butrous G, Taylor MB, et al. Intravenous sildenafil for postoperative pulmonary hypertension in children with pulmonary hypertension. Int Care Med. 2011;37:502-509.

83. Lee JE, Hillier SC, Knoderer CA. Use of sildenafil to facilitate weaning from inhaled nitric oxide in children with pulmonary hypertension following surgery for congenital heart disease. J Intensive Care Med. 2008;23(5):329-334.

84. Thusu KG, Morin FC 3rd, Russell JA, Steinhorn RH. The cGMP phosphodiesterase inhibitor zaprinast enhances the effect of nitric oxide. Am J Respir Crit Care Med. 1995;152(5 Pt 1):1605-1610.

85. Murray F, Patel HH, Suda RY, et al. Expression and activity of cAMP phosphodiesterase isoforms in pulmonary artery smooth muscle cells from patients with pulmonary hypertension: role for PDE1. Am J Physiol Lung Cell Mol Physiol. 2007;292(1):L294-L303.

86. Schermuly RT, Pullamsetti SS, Kwapiszewska G, et al. Phosphodiesterase 1 upregulation in pulmonary arterial hypertension: target for reverseremodeling therapy. Circulation. 2007;115(17):2331-2339.

\section{Publish your work in this journal}

Pediatric Health, Medicine and Therapeutics is an international, peerreviewed, open access journal publishing original research, reports, editorials, reviews and commentaries. All aspects of health maintenance preventative measures and disease treatment interventions are addressed within the journal. Practitioners from all disciplines are invited to submit

\section{Dovepress}

their work as well as healthcare researchers and patient support groups. The manuscript management system is completely online and includes a very quick and fair peer-review system. Visit http://www.dovepress. $\mathrm{com} /$ testimonials.php to read real quotes from published authors.

Submit your manuscript here: http://www.dovepress.com/pediatric-health-medicine-and-therapeutics-journal 